\title{
Tutorial and Simulation Electrooptic and Acoustooptic Software as Innovative Methodology to Improve the Quality of Electronic and Computer Engineering Formation
}

\author{
Pilar Martínez-Jiménez, Marta Varo-Martínez, Gerardo Pedros Perez, M. del Carmen García Martínez, \\ M. de la Salud Climent Bellido, M. Jesús Aguilera Ureña, and Jesús Fernández-Sánchez
}

\begin{abstract}
In this paper, an introduction to the main design features of a computer-aided educational package addressed to students of the final years of Electronic and Computer Engineering is presented. The software includes interrelated tutorial, computer simulations, and test questions in which graphical outputs, hypertexts, and animations are widely used. The package is devoted to the simulation study of electrooptic and acoustooptic theory and devices. It provides instant numerical evaluation and a graphical display of different studies. The software presented in this paper has all the following features: an integrative character, self-evaluation tests, a personalized and active learning process, adaptability to teacher's aims, versatility as a teaching tool, multimedia resources, and simplicity. This study has been completed with final-year students at the Superior Polytechnic School of Cordoba, Spain, with highly favorable results when compared with students who did not use the software.
\end{abstract}

Index Terms-Acoustooptic devices, collaborative work, educational technology, electrooptic devices, simulation software.

\section{INTRODUCTION}

$\mathbf{I}$ $\mathrm{N}$ the past few years, important changes have taken place in research areas related to the teaching of engineering [1], [2], and new models of didactic intervention, oriented toward the construction of significant knowledge, was introduced at the same time as the increase in the development and use of new information technology in education (computers, audiovisual media, and multimedia equipment) [3], [4].

In this context, numerous studies [5], [6] have demonstrated the benefits of the use of the new technologies at an educational level, such as instruments for resolving exercises and problems, tools for carrying out simulations of experiments and scientific phenomena [7], or tools for measuring and controlling laboratory experiments.

Some published works have shown the interesting possibilities offered by computer applications to promote the comprehension of concepts by means of the conceptual change

Manuscript received April 4, 2005; revised February 10, 2006.

The authors are with the Department Applied Physics, Avda. María Virgen y Madre, Escuela Politécnica Superior, Universidad de Córdoba, Córdoba 14071 SPAIN.

Digital Object Identifier 10.1109/TE.2006.873987 process [8]. Both solving problems and the approximation and performing of experiments by pupils can be considered guided activities [9]. Thus, the computer can be used as a reflection device, in which students are the protagonists of their own learning process [10], [11].

To improve the rate of success and to adapt the curricula of electronic and computer engineers to the requirements of new societal and industrial challenges, a new discipline (subject) in higher education was introduced at the Superior Polytechnic School of Cordoba University, Cordoba, Spain: Optical Communication Systems.

The course on Optical Communication Systems has a total of 45 hours assigned. The main topics treated are 1) optic, 2) electrooptic theory and devices, 3) acoustooptic theory and devices, 4) optic fiber, and 5) optic communication systems.

When the student faces this course, he or she has already received a sound basis in analog and digital electronics and basic courses in mathematics and physics.

In the general program of this discipline two thematic units have been included: electrooptics and acoustooptics.

In the normal course of the subject, throughout the first and second academic years (1996-1997 and 1997-1998); the teachers in charge noticed that students had difficulties in understanding these thematic units. This situation was aggravated because little didactic material on the theme existed even though an important investigation was developing [12]. To improve the level of teaching and encourage self-learning, a decision was made to develop a computer application (simulation laboratory) that would enable students to study all the basic theoretical aspects of these disciplines and permit the simulation and visualization of general problems and the behavior of the devices, obtaining both numerical and graphic results.

As a result, the research team carried out an educational project related to the development, application, and evaluation of an Electro-optic and Acousto-optic Multimedia Simulation Laboratory (EAMSL), in which a theoretical-practical study was conducted into basic principles of physics and the main electrooptic and acoustooptic devices.

The general aims intended in this process were as follows:

- to relate the theoretical and practical aspects of teaching; 


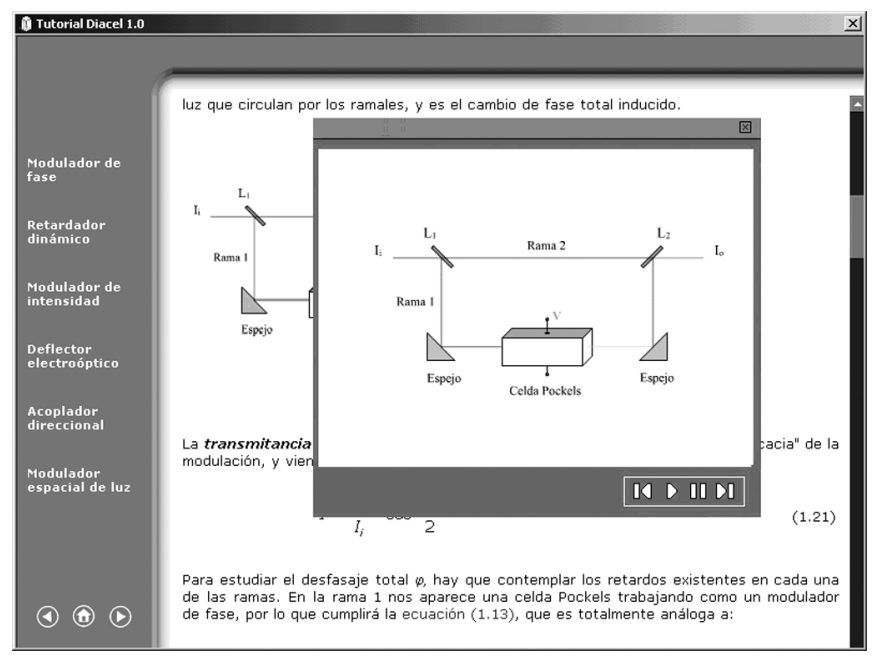

Fig. 1. Intensity modulator screen.

- to ensure that students obtain sufficient information on the nature and way to use the most important electrooptic/acoustooptic devices;

- to improve the self-learning process and induce a critical analysis of the results;

- to provide an active and more personalized education to motivate the student.

To achieve these ends, the research team has taken into consideration the results from the evaluation of work in previous years. The educational experiment was carried out with the final year of electrical and computer engineering students over two consecutive years.

In this paper, the design process of a first program and a summary of the results obtained in its experimentation is presented.

\section{DESCRIPTION OF THE SOFTWARE}

The software used in the experiment was developed in a Windows environment, using a multimedia programming tool (Microsoft VBasic 6.0).

The program is distributed via the Applied Physics Department of the Universidad de Córdoba, Córdoba, Spain, Web page on the Internet (http://rabfis15.uco.es/LVCT) and includes the install version (Diacel 1.0). Students can work with their personal computers or also connect to a local Universidad de Córdoba network, http://windows.uco.es. The operating system used is Windows 98/2000/XP/NT.

The application consists of three different parts that are connected to each other: tutorial, simulation, and help.

\section{A. Tutorial Module}

In this module, different concepts and basic principles of electrooptics and acoustooptics, related to the topics dealt in the EAMSL are explained by means of a hypertext (HTML) in illustrated and animated tutorials. Their objective is to expound, clearly and concisely, the principles ruling the interaction of the electric field and sound in materials presenting electrooptic and acoustooptic properties and the basic functioning of the most representative devices with a direct application of these effects. Fig. 1 shows the study and animation of an intensity modulator.

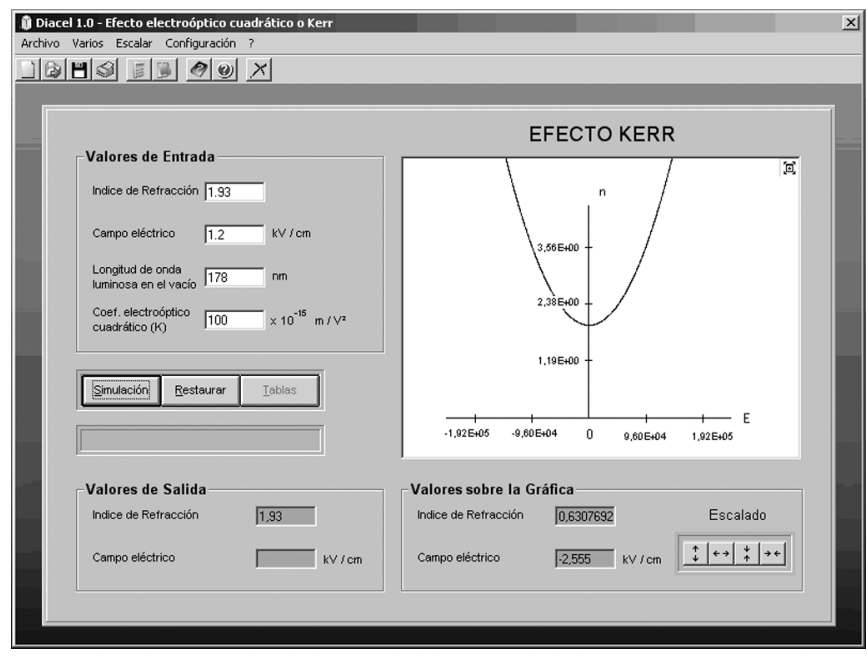

Fig. 2. Screen of Kerr effect simulation.

The tutorial ends with a questionnaire that aims to make students aware of having understood the concepts addressed. The questionnaire has a series of successive questions proposed to be answered.

\section{B. Help Module}

The help module consists of a series of documents in an HTML format, which explain the functioning of each of the sections making up the program.

\section{Simulation Laboratory Module}

This module is the most interesting one in the program from an educational point of view, since it permits students to perform simulated experiments following an activity program guide. In this module, a series of options corresponding to each of the cases is to be analyzed: Pockels effect, Kerr effect, phase modulator, phase retarder, intensity modulator, directional coupler, acoustooptic effect, and diffraction yield. As a study sample, the laboratory corresponding to the Kerr effect (Fig. 2) is considered. In it, the nonlinear dependence on certain electrooptic material as a function of the electric field applied is shown. In Fig. 3, the screen corresponding to the simulated study of the acoustooptic effect is also shown, namely, the harmonic variation in the refraction index of material with acoustooptic properties in terms of a sound wave.

These simulation screens have been designed to include vertical and horizontal buttons. In the horizontal quick-access buttons, apart from the usual operations of any application (that is, file, new open, print, etc.), a utility button is provided in which a call or quick access is established to other Windows tools, such as the calculator and word processor.

The vertical buttons include numerical entry values which, in the particular case of the Kerr effect (Fig. 4), are refraction index, quadratic electrooptic coefficient, and electric field.

When the curve has been generated by placing the cursor on the plotting area, a cross-hair is activated, moving about on the graph and generating dynamically the numerical starting values corresponding to each point. These starting values are transcribed in the fields refraction index and electric field. 


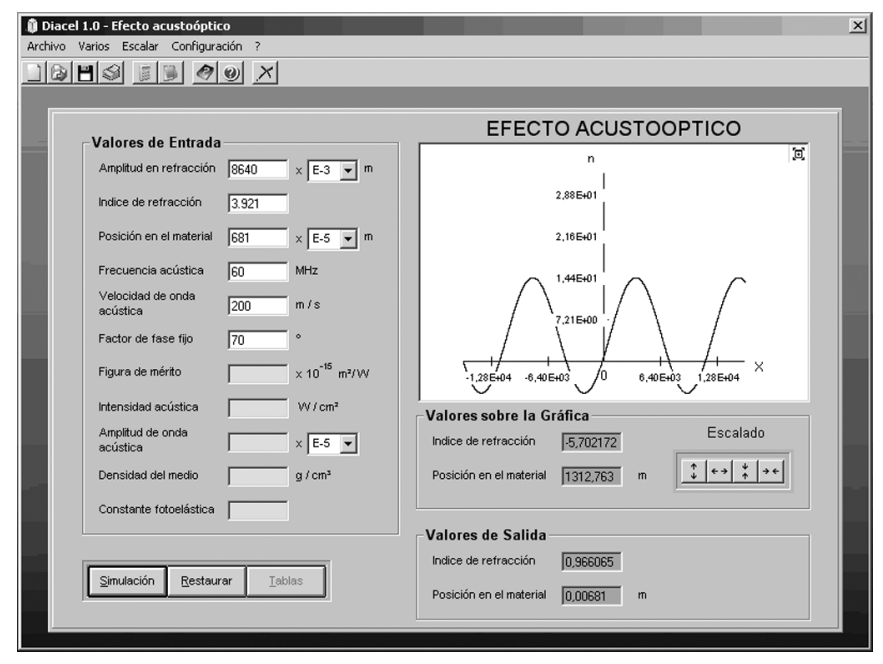

Fig. 3. Screen of acoustooptic effect simulation.

\begin{tabular}{|c|c|c|c|c|c|c|c|c|c|c|c|c|}
\hline \multirow{2}{*}{ Moterial } & \multirow{2}{*}{ Formula } & \multirow{2}{*}{ Stmetrio } & \multirow{2}{*}{$\begin{array}{l}\text { Loenotud } \\
\text { onde [nm] }\end{array}$} & \multicolumn{7}{|c|}{ Coefixiente edectrobptico lined [pmV] } & \multicolumn{2}{|c|}{ Indice de refrectibn } \\
\hline & & & & RIग & 1022 & 200 & RM & RQ2 & BSA & PES & Orisnario & Etrobed. \\
\hline 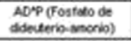 & $\operatorname{sim} D .904$ & inn & seg & & & & 0 & & & 119 & 152 & 1.97 \\
\hline 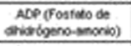 & $\mathrm{NH}+\mathrm{HPO}_{4}$ & $72 m$ & seg & & & & 245 & & & -85 & 152 & 1.49 \\
\hline $\operatorname{Acs}(C \cos 0 \mathrm{erta})$ & $\times 0 \times S_{2}$ & 4hn & sees & & & & 40 & & & 30 & 25s & 254 \\
\hline Artencirs de gosso & saso & ism & 548 & & & & is & & & 0 & 3.6 & 0 \\
\hline Eso(bentera) & $a_{4} \mathrm{P}_{2} \mathrm{O}_{2}$ & 830 & 200 & & & & 0.54 & & & 0 & 2.15 & 2.15 \\
\hline 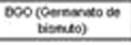 & $\mathrm{O}_{4}, \mathrm{OQ}_{3} \mathrm{O}_{12}$ & 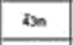 & $\infty$ & & & & 10 & & & 0 & $2 s s$ & 258 \\
\hline bod ofo of ibo & $\mathbf{H O}_{3}$ & 6 & es & 41 & & 6.4 & & 14 & 23 & & 18517 & 1.7100 \\
\hline 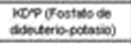 & 10,804 & ino & 500 & & & & os & & & 200 & 190 & 1.65 \\
\hline 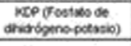 & $\mathrm{m}_{2} \mathrm{OO}_{4}$ & ano & $s e n$ & & & & os & & & 10.5 & 154 & 1.67 \\
\hline Nobedo do dito & Lneo, & 3n & ses & 26 & ? & 300 & & 26 & & & 229 & 220 \\
\hline Tretevisto do itis & vitoos & sn & sea & 84 & 0 & 305 & & o & & & 2.17 & 218 \\
\hline Ttenveo de berio & Bation & 490 & 500 & 8 & & 28 & & & 0 & & 2.41 & 238 \\
\hline \multirow[t]{2}{*}{ mercts } & Ins & $\mathrm{emm}$ & ses & 09 & & 18 & & 0 & 0 & & 2360 & 2360 \\
\hline & & & $\cos \alpha x$ & & & sane & & & & & & \\
\hline
\end{tabular}

Fig. 4. Table with complete examples (values of Rij and n).

By pressing Button for tables, a menu for selecting tables is accessed, which is common to the following simulation practices based on the electrooptic effect application: directional coupler, Pockels effect, and phase modulator (Fig. 4).

\section{Work Methodology With EAMSL}

The software described above is simple to use and, in addition, contains a help module that provides enough information for the user to handle satisfactorily. However, to try to improve this software's educational effectiveness, a program guide of activities is designed, which directs the students' interaction with the computer [13].

This program guide can be presented as an additional document in a text window of the Windows environment and is available in the Web at http://rabfis15.uco.es/deptfisica/eps/.

The first activity proposed in this program guide consists of accessing the questionnaire included in the tutorial module. Then, the students are to visualize the results, take note of the responses made by the program, and try to overcome the deficiencies in the previous knowledge of the theme. Then, a general review of the program's tutorial module should be completed.

The third overall activity, made up of a large set of specific tasks, consists of accessing the simulation module and performing virtually some simulations, such as the case of the study of the directional coupler or the diffraction yield, following the steps proposed by the program guide.

Finally, students are asked to reflect on the results obtained and to formulate their personal conclusions on the software's educational value.

For students using this program, the tasks of the greatest didactic interest correspond to the development of the third overall activity of the program guide in which students are invited to reflect and analyze what they are observing in the simulation.

\section{Development and Evaluation of EDUCATIONAL EXPERIMENT}

\section{A. Experimental Design of the Research Work}

In addition to developing didactic software, one must apply the programs elaborated in real educational contexts and evaluate their influence on the acquisition of scientific knowledge through educational research processes [13], as it has been done with the students of Optic Communications Systems.

To identify the degree of reliability of the tool used and its influence on the lecturing improvement of these subjects, four groups of the total number of students were established. Two of these groups followed a traditional teaching method $\{$ control groups $\mathrm{GC} 1(n=14)$ and $\mathrm{GC} 2(n=16)\}$, based on a theoretical exposition and classroom practice. The other two groups were given the same theoretical-practical contents, using the EAMSL as a complementary tool in the learning process \{experiment groups GE1 $(n=15)$ and GE2 $(n=15)\}$.

The lecturer team has, therefore, proposed one main research objective: to contrast the results in training acquired by students when working with the simulation laboratory, and when receiving traditional teaching only.

To make a quantitative assessment the teachers look at four objectives related to the learning concept procedures of students when working with or without the aid of the software described above. These specific objectives are as follows:

1) to learn about the physical basics of the electrooptic and acoustooptic behavior of certain materials;

2) to differentiate linear electrooptic behavior or Pockel effect from the quadratic electrooptic behavior or Kerr effect;

3) to acquire the necessary knowledge to determine the basics of the behavior of different electrooptic and acoustooptic devices;

4) to relate the theoretical-practical aspects to solve practical problems.

\section{B. Description of the Process Followed in the Experimental Stages}

The following is the process followed. 
1) Lecture Section (common to the four groups, in which the fundamental concepts related to the two themes are explained: Students have previous written information on these concepts.

2) Classroom Practice: Here, the problems proposed and later solved by students are commented upon and discussed, with the class being given to each group individually. The control groups have two hours per week.

The experiment groups have one hour weekly of problems and two hours every two weeks of laboratory simulation. The students are provided with a program guide in which the process to follow and the problems to be solved through a simulation are provided. All the questions they may have are resolved by the lecturer giving the simulation laboratory practice.

The students in the control groups are given the same practical cases as are the experiment groups, and they can solve them in small groups in the practice class under the supervision of the class lecturer.

After working with the software, the students from the experiment groups did the same practice works as the control group students. On finalizing this process, each student gives a written report in which he or she shows and analyzes the results obtained, reaches conclusions, and answers diverse questions related to the student's interpretation of the proposed problems.

To complete the study made with the control and experimental groups, a set of questions and exercises that students must resolve individually follows the instruction. These exercises are practical problems that require the revision of prior theoretical information.

The time devoted to the study of these themes was similar in all the groups since the experiment group students substituted one hour of classroom practice for the laboratory simulation. The experiment groups had the advantage of being able to consult the tutorial related to any specific question on a simulation during the practice exercise. Other advantages shown in using the software are 1) the ability to repeat an experiment simulation rapidly many times and 2) the ability of the student to access the tutorial questionnaire and receive a diagnosis on the level of learning at each moment.

\section{Evaluation of the Experiment}

To make an evaluation of the development of this educational experiment (i.e., to study the degree of satisfaction in the achievements of the educational objectives proposed), an evaluation was made of the learning acquired by each of the students of control groups $\mathrm{GC} 1$ and $\mathrm{GC} 2$ and of those in the experiment groups GE1 and GE2. The following aspects were reviewed:

1) the quality of the work reports drafted by students at the end of the virtual laboratories (experiment groups) and the work presented by control group students concerning the practical cases resolved in the practice classes (between 0 and 10 points);

2) the results of a set of questions and exercises that students had to resolve individually (between 0 and 10 points);

3 ) the results of a written test made up of several questions, in which students had to demonstrate that they can relate

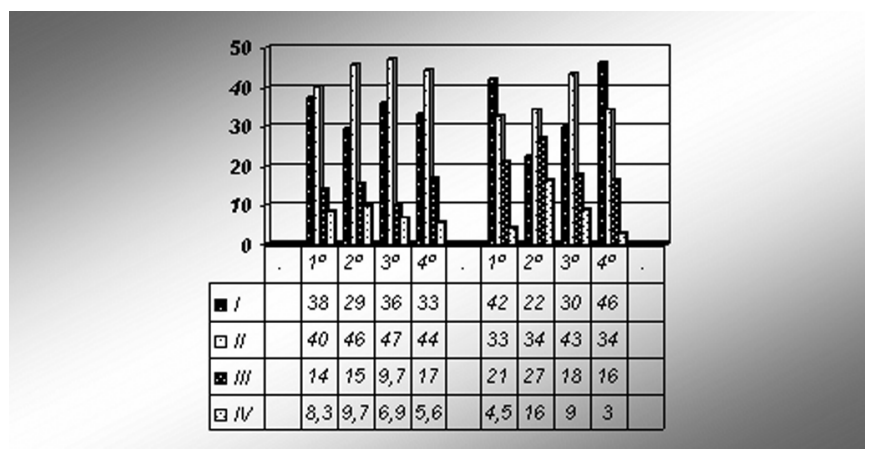

Fig. 5. Results of learning objective evaluation in the control groups.

the theoretical-practical aspects involved in the study (between 0 and 10 points: 1 point/ 1 true question, 0 point/no answered question and (-1)/wrong question);

4) the results of an exam in which a practical problem was proposed (between 0 and 10 points).

In addition, to evaluate the overall performance of each student, the marks corresponding to the four objectives were added together so that each student had a scoring capacity of between 0 and 40 points.

From these partial marks, overall categories or learning levels can be defined, and one can plot the differences in graphs and reach conclusions about the completion of the experiment, as will be seen later. Statistical processing can also illustrate the performance differences among the groups. Specifically, the Kruskal-Wallis test [14] was applied. Those results are commented on later.

\section{Analysis of Results}

For the study of the evaluation results for each of the objectives, the partial marks assigned to the students in the different groups is taken. For each one, four categories or levels of learning have been established according to the following classification: category I corresponded to very low marks (deficient learning between 0 and 5 points); category II, to average marks (fair or semiacceptable learning between 5 and 7 points); category III, to high marks (good learning level: between 7 and 9 points); and category IV, to very high marks (very good learning level between 9 and 10 points).

Fig. 5 shows the results obtained by the students in the control groups $\mathrm{GC} 1$ and $\mathrm{GC} 2$, corresponding to the evaluation of the four objectives (1, 2, 3, and 4), allocated to categories (I, II, III, and IV). The relative frequencies or percentages corresponding to each of the four levels established for each objective and group are shown in columns, those on the left being for group GC1 and on the right, those for group GC2. The results obtained by both groups are fairly similar. On comparing the results from $\mathrm{GC} 1$ and $\mathrm{GC} 2$ in each of the four objectives, one observes that some differences were present in the different categories, but in the statistical contrast, no statistically significant differences in any of the objectives were noted in a study made between the average marks of each group. This outcome means that both groups had developed a similar learning process and had reached a similar performance level. 


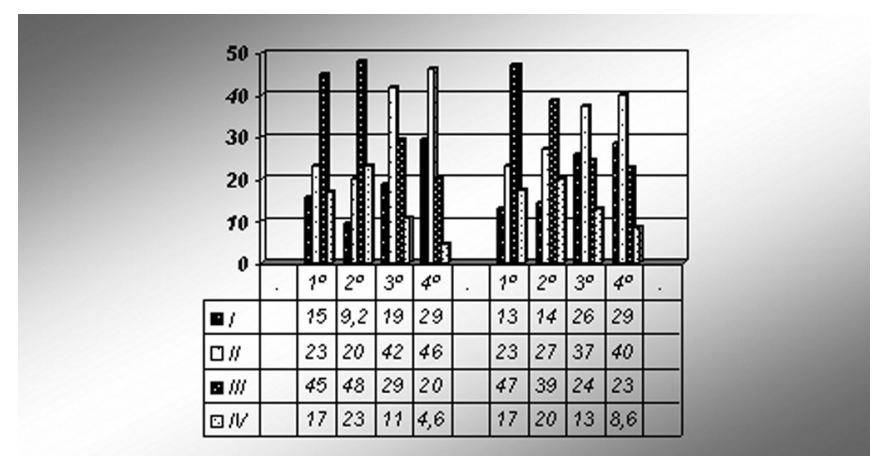

Fig. 6. Results of learning objective evaluation in experiment groups.

In the experiment groups, the same evaluation process was followed as in the control groups. Fig. 6 shows the results obtained by the students in these groups, on the left are the GE1 group data, and on the right, those of group GE2. This figure also shows that the results obtained by both groups present a similar allocation of percentages to the different categories of the objectives evaluated. Moreover, in the statistical contrast study made between the average marks of each group, no statistically significant differences were noticed in any of the objectives. This discovery was logical because both groups had the same initial characteristics, had carried out a similar study process, and had reached a similar performance level.

In order to analyze the influence of the methodology followed in the experiment groups, a comparison was made of the results of these groups (Fig. 6) with those previously obtained by the control groups (Fig. 5).

For instance, on analyzing the data of the first and second objectives, one observes that the percentages of categories I and II were much higher in the control groups than in the experiment groups, suggesting a shift in the number of students from groups GE1 and GE2 who had achieved these objectives compared with those who had not in groups GC1 and GC2. Likewise, on applying several statistical contrast tests, one notes significant differences between the average values of the marks obtained in objectives 1 and 2 in the experiment groups. This analysis led to the consideration of the use of the software described and to its contribution toward improving knowledge about the physical fundamentals in the experiment group of students.

With regard to the third and fourth objectives, the comparative analysis in Figs. 5 and 6 show that the results were also better in the experiment groups than in the control groups so that one can say that the use of software favored the development of the procedures and skills necessary for the resolution of the questions and the practical problems.

Finally, the research team proceeded to evaluate and categorize the general performance of each student from the different groups, analyzing the set of data obtained throughout the experiment. To elicit an overall mark, the marks corresponding to the four objectives were totaled so that each individual had a mark of between 0 and 40 points. With the same procedure as above, four overall performance levels were established, as follows: $\mathrm{L}_{\mathrm{I}}$

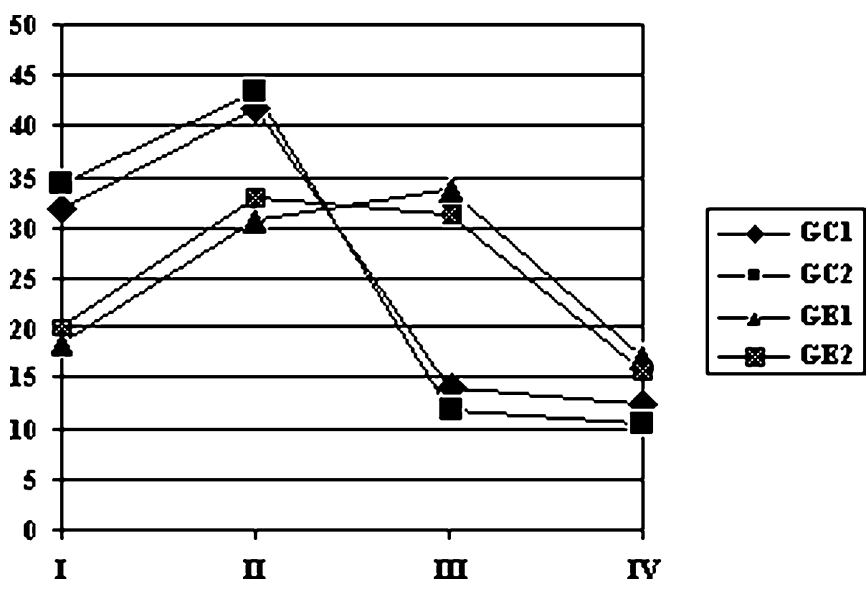

Fig. 7. Comparative study of grade frequency versus the different marks for each of the groups participating in the study.

(overall mark between 0 and 10 or deficient learning capacity), $\mathrm{L}_{\mathrm{II}}$ (overall mark between 10 and 20 or semiacceptable learning capacity), $\mathrm{L}_{\text {III }}$ (overall mark between 20 and 30 representing a good level of learning), and $\mathrm{L}_{\mathrm{IV}}$ (overall mark between 30 and 40 , corresponding to an optimal or very good learning result).

Fig. 7 shows the overall results of the four groups, with the percentages of the four performance levels in each group. First, one can see that the control groups GC1 and GC2 have very similar results in the four levels. The same happens in the results of the experiment groups GE1 and GE2, although these groups present a better overall performance than the previous ones. Indeed, levels $\mathrm{L}_{\mathrm{I}}$ and $\mathrm{L}_{\mathrm{II}}$ show a higher percentage in the control groups with respect to the experiment groups. On the contrary, in level $\mathrm{L}_{\mathrm{III}}$, the experiment groups obtained much better results than the control groups (with differences of over 20\% among these groups). Finally, in level $\mathrm{L}_{\mathrm{IV}}$, all the groups reach similar, although low, percentages, indicating that an optimal performance level both for the control groups and the experiment groups was difficult to achieve.

From a statistical processing of the overall marks of the four groups (with a Kruskal-Wallis test [14]), the use of the simulation laboratory appears to favor the training of the average student and causes a shift in results from the grades of "deficient" and "acceptable" to "good" in the experiment groups.

Finally, the similarity in the results obtained in level $\mathrm{L}_{\mathrm{IV}}$ was the result of a few students in each group with a higher level of specific knowledge and a greater interest in the subject, regardless of the teaching methodology.

From these facts, one can conclude that the instruction process followed in the experiment groups enabled students to achieve a higher progress level than in the control groups and that the program used is a useful aid for improving the learning process. These facts would appear to confirm the results obtained in other studies showing the favorable influence of the use of simulation programs in the teaching of physics and of other sciences [15], [16]. In addition, the research group is developing a new Spanish and English online version of DIACEL. 


\section{Final Conclusion and Considerations}

In this paper, an empirical educational piece of research has been described. The authors have concluded that the use of an Electro-optic and Acousto-optic Simulation Laboratory (EAMSL) can be used by students for better comprehension of the main concepts of this study and can especially contribute to improving the work of those students who have the greatest learning deficiencies.

The software described is compact, intuitive, and friendly, thus constituting an effective new tool for introducing students to electrooptic and acoustooptic science.

Computer simulations of fundamental concepts and devices are an important part of the software. In the simulations, the students play an active role by setting up and changing the experiment situations according to the tasks to be solved.

This software has been used with final-year university students with good results. After completing the study described here, the results of this study compares favorably with previous studies [3]-[5].

The use of this simulation laboratory as a learning aid that complements the traditional method has the following advantages.

- It permits the reflective self-training of students through their individual work, either as a clarification and complement to experiment laboratories or as a practical task in itself.

- It permits teachers to focus on the explanation of the basic theories and reduces the time that, at present, is devoted to introducing the mode of operation and working.

\section{ACKNOWLEDGMENT}

The authors are grateful to British teacher of English D. Badder and American teacher of English D. Vaughan for reviewing the English.

\section{REFERENCES}

[1] C. L. Dym, "Design, systems, and engineering education," Int. J. Eng. Educ., vol. 20, no. 3, pp. 305-312, May 2004.

[2] F. G. Splitt, "The challenge to change: on realizing the new paradigm for engineering education," J. Eng. Educ., vol. 92, no. 2, pp. 181-187, April 2003.

[3] P. Martinez-Jimenez, E. Casado, J. M. Martinez-Jimenez, M. Cuevas-Rubino, D. Gonzalez-Caballero, and F. Zafra-Lopez, "Interactive physics simulations appeal to first-year students," Comput. Phys., vol. 11, pp. 31-36, 1997.

[4] P. Martinez-Jimenez and E. Casado, "Electros: development of an educational software for simulation in electrostatic," Comput. Appl. Eng. Educ., vol. 12, no. 1, pp. 65-73, May 2004.

[5] A. J. Lopez Martin, "Web-based remote of communication systems: A successful experience," Int. J. Electr. Eng. Educ., vol. 40, no. 3, pp. 169-174, Jul. 2003.

[6] R. Lelouche, "How education can benefit from computer: A critical review," in Proc. 4th Int. Conf. Computer-Aided Learning Instruction in Science Engineering (CALISCE), 1998, pp. 19-32.

[7] E. Casado-Revuelta, P. Martínez-Jiménez, A. Blanca-Pancorbo, J. LeónAlvarez, M. Cuevas-Rubiño, and D. Gonzalez-Caballero, "Design of an environment for physical phenomena simulation: Application to visualization and animation of electrostatic field and potential," in Proc. IEEE 28th Annu. Simulation Symp., Santa Barbara, CA, Apr. 25-28, 1995, pp. 201-209.
[8] P. W. Hewson, "Diagnosis and remediation of an alternative conception of velocity using a microcomputer program," Amer. J. Phys., vol. 53, no. 7, pp. 684-690, Jul. 1985.

[9] $\mathrm{H}$. Li, "Information-technology-based tools for reengineering construction engineering education," Comput. Appl. Eng. Educ., vol. 6, no. 1, pp. 15-21, 1998.

[10] R. B. Hicks and H. Laue, "A computer-assisted approach to learning physics concepts," Amer. J. Phys., vol. 57, no. 9, pp. 807-811, 1989.

[11] L. C. McDermott, "A perspective on teacher preparation in physics and other sciences-The need for special science courses for teachers," Amer. J. Phys., vol. 58, no. 8, pp. 451-462, 1990.

[12] C. Aupetit-Berthelemot, A. Dubois, and J. L. Verneuil et al., "System simulation: a tool to validate the insertion of electro-optic devices into a 40 Gbit/s fiber-optic link," Annales des Telecommunications-Annals Telecommun., vol. 58, no. 9-10, pp. 1504-1539, Sep.-Oct. 2003.

[13] H. Hassan, J. M. Martínez, C. Domínguez, A. Perles, and J. Albadalejo, "Innovate methodology to improve the quality of electronic engineering formation through teaching industrial computer engineering," IEEE Trans. Educ., vol. 47, no. 4, pp. 446-452, Nov. 2004.

[14] R. Lowry. (2003, Dec.) The Kruskal-Wallis Test for 3 or More Independent Samples. [Online]. Available: http://faculty.vassar.edu/ lowry/PDF/c14a.pdf

[15] W. J. Lee, J. C. Gu, and R. J. Li et al., "A physical laboratory for protective relay education," IEEE Trans. Educ., vol. 45, no. 2, pp. 182-186, May 2002

[16] V. M. Becerra, "Solving optimal control problems with state constraints using nonlinear programming and simulation tools," IEEE Trans. Educ., vol. 47, no. 3, pp. 377-384, Aug. 2004.

Pilar Martínez-Jiménez is a Professor Doctor in the Applied Physics Department of Universidad de Córdoba, Córdoba, Spain. She is also the Director of the Scientific and Technology Virtual Laboratory (LVCT) research group. Her research interests include virtual laboratories software, visual programming, collaborative work, educational technology, and renewable energy. She has coauthored ten books and published research papers in international conferences and journals, including Computers in Physics, the Journal Chemical Education, Lecture Notes in Computer Science, Computer Application in Engineering Education, and the Journal of Applied Physics.

Marta Varo-Martínez is currently working toward the Ph.D. degree at the Universidad de Córdoba, Córdoba, Spain.

Since 2003, she has been a Physicist with the Applied Physics Department, Universidad de Córdoba. Her research interests are divided into two different lines: ultraviolet solar radiation, on which her thesis is focused, and virtual laboratories software, visual programming, collaborative work, and educational technology. She has coauthored several papers for national and international conferences and journals.

Gerardo Pedros Perez is a Professor Doctor in the Applied Physics Department of Universidad de Córdoba, Córdoba, Spain. His research interests include virtual laboratories software, visual programming, collaborative work, renewable energy, and educational technology. He has coauthored 13 books and published research papers in international conferences and journals, including the Journal of Geophysical Research, Energy, Renewable Energyand Lecture Notes in Computer Science.

M. del Carmen García Martínez is a Professor Doctor in the Applied Physics Department of Universidad de Córdoba, Córdoba, Spain. Her research interests include virtual laboratories software, visual programming, collaborative work, educational technology, and plasma spectroscopy. She has coauthored numerous books and published research papers in international conferences and journals, including Spectrhochimica Acta Part B, the Journal of Applied Physics, and Applied Spectroscopy. 
M. de la Salud Climent Bellido is a Professor Doctor in the Chemistry Organic Department of Universidad de Córdoba, Córdoba, Spain. Her research interests include virtual laboratories software, visual programming, collaborative work, organic chemistry, and educational technology. She has coauthored four books and published research papers in international conferences and journals, including the Journal of Organic Chemistry, Tetrahedrom, and the Journal Chemical Education

M. Jesús Aguilera Ureña is a Professor Doctor in the Applied Physics Department of Universidad de Córdoba, Córdoba, Spain. She is a member of the New Technologies Applied to Agriculture and Environment research group, and she works in applications of satellite positioning systems, especially in geodesy, with the development of educational software related to that topic.
Jesús Fernández-Sánchez has been studying Computer Science Engineering in the Universidad de Córdoba, Córdoba, Spain, since 2003. He has been working on developing a decision support system for weed growth in wheat crops for an agronomical institute with a grant from the Spanish Science Council and on the development of Web applications and server maintenance with support from the Physics Department of the Universidad de Córdoba. 